\title{
Effects of two commercially available feline diets on glucose and insulin concentrations, insulin sensitivity and energetic efficiency of weight gain
}

\author{
M. Coradini ${ }^{1 *}$, J. S. Rand ${ }^{1}$, J. M. Morton ${ }^{1} \dagger$ and J. M. Rawlings ${ }^{2}$ \\ ${ }^{1}$ Centre for Companion Animal Health, School of Veterinary Science, The University of Queensland, Saint Lucia, Brisbane, \\ QLD 4072, Australia \\ ${ }^{2}$ WALTHAM Centre for Pet Nutrition, Melton Mowbray, Leicestershire LE14 4RT, UK
}

(Received 2 November 2010 - Revised 4 August 2011 - Accepted 10 August 2011)

\section{Abstract}

A low-carbohydrate, high-protein (LCHP) diet is often recommended for the prevention and management of diabetes in cats; however, the effect of macronutrient composition on insulin sensitivity and energetic efficiency for weight gain is not known. The present study compared the effect in adult cats ( $n$ 32) of feeding a LCHP (23 and $47 \%$ metabolisable energy (ME)) and a high-carbohydrate, low-protein (HCLP) diet (51 and $21 \%$ ME) on fasting and postprandial glucose and insulin concentrations, and on insulin sensitivity. Tests were done in the 4th week of maintenance feeding and after 8 weeks of ad libitum feeding, when weight gain and energetic efficiency of each diet were also measured. When fed at maintenance energy, the HCLP diet resulted in higher postprandial glucose and insulin concentrations. When fed ad libitum, the LCHP diet resulted in greater weight gain $(P<0 \cdot 01)$, and was associated with higher energetic efficiency. Overweight cats eating the LCHP diet had similar postprandial glucose concentrations to lean cats eating the HCLP diet. Insulin sensitivity was not different between the diets when cats were lean or overweight, but glucose effectiveness was higher after weight gain in cats fed the HCLP diet. According to the present results, LCHP diets fed at maintenance requirements might benefit cats with multiple risk factors for developing diabetes. However, ad libitum feeding of LCHP diets is not recommended as they have higher energetic efficiency and result in greater weight gain.

Key words: Diet effect: Cats: Glucose and insulin: Weight gain

There are currently a large number of diets available commercially for cats, which vary greatly in nutrient composition. Cats are strict carnivores and do not metabolise carbohydrates efficiently ${ }^{(1-5)}$. The typical prey diet of cats is low in carbohydrate $(<10 \% \text { metabolisable energy }(\mathrm{ME}))^{(6)}$; however, most commercially available dry cat foods are moderate to high in carbohydrate content ( $>25-55 \% \mathrm{ME}$ ), partly because of the difficulty in formulating extruded, dry diets that are low in carbohydrate, and partly because cereal is a relatively inexpensive ingredient, and there is demand for lower-cost diets in the pet food market.

Low-carbohydrate, high-protein (LCHP) diets have been reported in research abstracts and in a recent publication to significantly reduce the postprandial increase in blood glucose concentration compared with high-carbohydrate, low-protein (HCLP) diets (Farrow HA, Rand JS and Sunvold GD (2002); Singh R, Rand J and Morton J (2006), unpublished results) ${ }^{(7)}$, possibly indicating a reduced demand on the $\beta$-cells to produce insulin. A LCHP diet has also been shown to reduce the need for exogenous insulin administration in diabetic cats ${ }^{(8)}$. Diabetes in cats is similar to human type 2 diabetes, characterised by decreased insulin secretion and insulin resistance ${ }^{(9,10)}$, and it has been hypothesised that a high-carbohydrate diet fed long term potentially might be a risk factor for the development of diabetes mellitus in cats ${ }^{(11)}$.

Increased body fat mass in cats is associated with decreased insulin sensitivity and hyperinsulinaemia, and is a known risk factor for feline diabetes ${ }^{(12,13)}$. In neutered cats, weight gain is positively correlated with the percentage of dietary fat ${ }^{(14)}$. Both hyperglycaemia and insulin resistance increase the demand on the pancreatic $\beta$-cells to produce insulin to maintain glucose homeostasis, ultimately predisposing to $\beta$-cell failure and overt diabetes ${ }^{(15)}$. As in humans, healthy cats demonstrate a range of underlying insulin sensitivities ${ }^{(13)}$. Cats with insulin sensitivities below a study population median were found to be at increased risk of developing impaired glucose tolerance with obesity, and presumably with sufficient time, or imposition of another risk factor such

Abbreviations: HCLP, high-carbohydrate, low-protein; LCHP, low-carbohydrate, high-protein; ME, metabolisable energy

*Corresponding author: M. Coradini, fax +6173346 9822, email m.coradini@uq.edu.au

† Present address: PO Box 2277, Geelong, VIC, Australia. 
Table 1. Diet analyses, main ingredients, digestibility and energetic density of each diet

\begin{tabular}{|c|c|c|c|}
\hline \multirow[b]{2}{*}{ Variables } & \multicolumn{3}{|c|}{ Diet } \\
\hline & Baseline* & LCHP† & HCLP \\
\hline \multicolumn{4}{|l|}{ Key values (as-fed basis \%) } \\
\hline Moisture & 8.0 & $7 \cdot 0$ & $7 \cdot 3$ \\
\hline Protein & 28.7 & $46 \cdot 0$ & 21.5 \\
\hline Fat & $11 \cdot 0$ & $12 \cdot 0$ & $11 \cdot 7$ \\
\hline NFE§ & $42 \cdot 1$ & $22 \cdot 8$ & $51 \cdot 0$ \\
\hline Dietary fibre & 7.4 & $11 \cdot 0$ & $10 \cdot 4$ \\
\hline Crude fibre & 1.8 & $5 \cdot 5$ & $2 \cdot 2$ \\
\hline Ash & 8.5 & $6 \cdot 7$ & $6 \cdot 3$ \\
\hline Arg & 1.5 & $2 \cdot 4$ & 1.3 \\
\hline Taurine & 0.1 & 0.2 & 0.1 \\
\hline Lys & 1.0 & $2 \cdot 0$ & 0.9 \\
\hline Met & 0.7 & $1 \cdot 2$ & 0.3 \\
\hline Cystine & 0.5 & 0.6 & 0.5 \\
\hline Hydroxyproline & 0.3 & 0.8 & 0.3 \\
\hline Linoleic acid & $2 \cdot 3$ & $3 \cdot 1$ & 1.4 \\
\hline Linolenic acid & 0.2 & - & 0.2 \\
\hline$n-3$ & 0.01 & 0.7 & 0.01 \\
\hline$n-6$ & 0.03 & 3.5 & 0.02 \\
\hline $\mathrm{Ca}$ & 1.3 & 0.9 & 1.3 \\
\hline $\mathrm{P}$ & 1.0 & 0.9 & $1 \cdot 1$ \\
\hline $\mathrm{Na}$ & 0.9 & 0.4 & 0.7 \\
\hline $\mathrm{Cl}$ & $1 \cdot 1$ & 1.3 & $1 \cdot 1$ \\
\hline $\mathrm{K}$ & 0.8 & 1.0 & 0.8 \\
\hline $\mathrm{Mg}$ & $0 \cdot 1$ & 0.1 & 0.2 \\
\hline $\begin{array}{l}\text { Chondroitin sulphate }+ \\
\text { glucosamine }\end{array}$ & - & 0.1 & - \\
\hline L-Carnitine & - & 0.01 & - \\
\hline \multicolumn{4}{|l|}{ Main ingredients } \\
\hline Poultry viscera & Yes & - & Yes \\
\hline Poultry liver & - & Yes & - \\
\hline Poultry meal & Yes & Yes & Yes \\
\hline Turkey meal & Yes & - & - \\
\hline Feather meal & - & - & Yes \\
\hline Fishmeal & - & - & Yes \\
\hline Soya meal & Yes & - & Yes \\
\hline Maize meal & - & Yes & - \\
\hline Poultry fat & - & Yes & - \\
\hline Soya protein isolate & - & Yes & - \\
\hline Wheat & - & - & Yes \\
\hline Whole maize & Yes & - & - \\
\hline Maize gluten & Yes & Yes & - \\
\hline Barley & - & Yes & - \\
\hline Broken rice & Yes & - & - \\
\hline Tallow & Yes & - & Yes \\
\hline Taurine & Yes & Yes & Yes \\
\hline Calcium carbonate & Yes & - & - \\
\hline Citric acid & Yes & - & Yes \\
\hline Vitamin mixture\|l & Yes & Yes & Yes \\
\hline Mineral mixture & Yes & Yes & Yes \\
\hline Beet pulp & - & Yes & - \\
\hline Plant fibre & _- & Yes & - \\
\hline Psyllium seeds & - & Yes & - \\
\hline Fish oil & - & Yes & - \\
\hline Fructo-oligosaccharides & - & Yes & - \\
\hline Vegetable oil & - & Yes & - \\
\hline Potassium chloride & Yes & - & Yes \\
\hline Potassium citrate & - & Yes & - \\
\hline Green tea and grape extracts & - & Yes & - \\
\hline Chondroitin sulphate & - & Yes & - \\
\hline Glucosamine chloride & - & Yes & - \\
\hline L-Carnitine & - & Yes & _- \\
\hline Marigold flower extract & - & Yes & - \\
\hline $\begin{array}{l}\text { Mean apparent digestibility } \\
(\mathrm{DM} \%)^{\star *}\end{array}$ & $79 \cdot 3$ & $79 \cdot 6$ & 79.9 \\
\hline \multicolumn{4}{|l|}{ Energetic density (ME) } \\
\hline Total $(\mathrm{kJ} / 100 \mathrm{~g})$ (NRC 2006)†† & 1,518 & 1,552 & 1550 \\
\hline Total $(\mathrm{kJ} / 100 \mathrm{~g})(\mathrm{NRC} 1985) \neq \ddagger$ & 1,427 & 1,434 & 1,478 \\
\hline
\end{tabular}

Table 1. Continued

\begin{tabular}{|c|c|c|c|}
\hline \multirow[b]{2}{*}{ Variables } & \multicolumn{3}{|c|}{ Diet } \\
\hline & Baseline* $^{*}$ & LCHP† & HCLP‡ \\
\hline 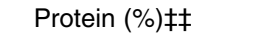 & 29 & 47 & 21 \\
\hline 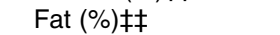 & 27 & 30 & 28 \\
\hline 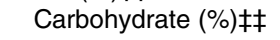 & 43 & 23 & 51 \\
\hline \multicolumn{4}{|c|}{$\begin{array}{l}\text { LCHP, low carbohydrate, high protein; HCLP, high carbohydrate, low protein } \\
\text { NFE, nitrogen-free extract; ME, metabolisable energy; NRC, National Research } \\
\text { Council. }\end{array}$} \\
\hline \multicolumn{4}{|c|}{ *Whiskas Adult with Vita-Bites, Mars Petcare (Raglan, NSW, Australia). } \\
\hline \multicolumn{4}{|c|}{$\begin{array}{l}\text { † Kitekat Krunch, Mars Petcare. } \\
\text { † }\end{array}$} \\
\hline \multicolumn{4}{|c|}{$\begin{array}{l}\text { \$ NFE }=100-\text { (moisture }+ \text { protein }+ \text { fat }+ \text { crude fibre }+ \text { ash). } \\
\text { lu Included vitamins } A \text {. }\end{array}$} \\
\hline \multicolumn{4}{|c|}{$\begin{array}{l}\text { Included vitamins } A, D_{3} \text {, E, thiamin, riboflavin, pantothenic acid, niacin, pyridox- } \\
\text { ine, folic acid, cyanocobalamin, choline and biotin. Vitamin } C \text { was included in the } \\
\text { LCHP diet. }\end{array}$} \\
\hline \multicolumn{4}{|c|}{ I Included $\mathrm{Ca}, \mathrm{P}, \mathrm{K}, \mathrm{Na}, \mathrm{Cl}, \mathrm{Mg}$, and trace elements $\mathrm{Fe}, \mathrm{Cu}, \mathrm{Mn}, \mathrm{Zn}$, I and Se. } \\
\hline \multicolumn{4}{|c|}{$\begin{array}{l}\text { ** Apparent percentage of DM digestibility }=(\text { food ingested }(\mathrm{g}) \text { - faeces produced } \\
(\mathrm{g})) \times 100 / \text { food ingested }(\mathrm{g}) \text {, calculated on a DM basis. } \\
+\dagger \text { Calculated using the equation proposed by the NRC }{ }^{(50)} \text {. }\end{array}$} \\
\hline
\end{tabular}

as steroid administration, were at increased risk of developing type 2 diabetes $^{(13)}$.

The effect of dietary macronutrient composition on fasting and postprandial plasma glucose and insulin concentrations over $24 \mathrm{~h}$ after eating has been inadequately investigated in cats, and it is not known how diet might affect insulin sensitivity and energetic efficiency for weight gain.

It was hypothesised that compared with a LCHP diet, feeding a HCLP diet to cats results in higher postprandial glucose and insulin concentrations, and is associated with lower insulin sensitivity, but may result in lower weight gain when fed ad libitum.

The aims of the present study were to compare the effect of feeding two commercially available diets, LCHP and HCLP diet, first, in ideal weight, clinically healthy cats and, second, after 8 weeks of ad libitum feeding to promote weight gain. Specific variables of interest were dietary effects on insulin sensitivity, fasting and postprandial plasma glucose and insulin concentrations before and after weight gain, and energetic efficiency of weight gain.

\section{Materials and methods}

\section{Animals}

A total of thirty-two neutered, lean, mixed breed cats (sixteen males, sixteen females) were used in the study. Accurate ages were unknown, but estimated to be from 2-4 years based on visual and physical examination, including examination of dentition. Cats were sourced from a municipal pound and all were rehomed at the end of the study.

Cats were considered healthy based on clinical examination, haematological and serum biochemical profiles, and a negative feline immunodeficiency virus test (Agen Biomedical Limited, Brisbane, QLD, Australia). Mean body condition score was 4.9 (range 4-5) on a nine-point body condition system $^{(16)}$. Mean body weight was 3.31 (SD 0.82) kg. The study protocol, care and handling of the animals were 
approved by the University of Queensland's Animal Ethics Committee under the Animal Welfare Act of the State of Queensland and the WALTHAM Ethical Review Committee (approval no. SVS/328/06/ARC). Cats were housed in environmentally enriched rooms for 12 weeks before and during the study. At 4 weeks before the beginning of the study, cats were individually housed and allowed at least $4 \mathrm{~h}$ of socialisation and exercise daily.

\section{Experimental design}

\section{Dietary treatments}

The present study used commercially available, extruded, dry diets that complied with the Association of American Feed Control Officials standards for complete and balanced feline diets. The following three diets were used in the study: diet 1 was a 'washout' or baseline diet, moderate in carbohydrate, fat and protein; diet 2 was a LCHP diet; diet 3 was a HCLP diet. A list of ingredients used in each diet is shown in Table 1. Dietary analysis was performed by an independent laboratory (DTS Food Laboratories, Kensington, VIC, Australia) accredited by the National Association of Testing Authorities. Digestibility trials were performed according to the Association of American Feed Control Officials' guidelines by the manufacturers (diets 1 and 3: Mars Petcare, Raglan, NSW, Australia; diet 2: Royal Canin, Aimargues, France), and involved six adult cats fed at maintenance energy requirements. The study consisted of three phases (Table 2).

In the baseline phase, all cats were fed the baseline or 'washout' diet for 4 weeks, which was moderate in carbohydrate and protein (Table 1), and energy intake was restricted to maintain the cats' body weight within 95-105\% of their initial weight. Baseline testing was conducted in the 4 th week of feeding (Table 2). In the second week of feeding the baseline diet, food was withheld for $24 \mathrm{~h}$, and a $2 \mathrm{ml}$ fasting blood sample was collected from the jugular vein, to determine each cat's insulin sensitivity status based on the simple measure of insulin sensitivity, the fasting glucose: insulin ratio ${ }^{(17)}$. Cats were then paired based on sex, insulin sensitivity and body weight. Immediately after the baseline testing in the 4th week, cats within each pair were randomly allocated to receive either the LCHP diet or the HCLP diet (Table 1). Random allocation was done by drawing numbers corresponding to each cat; the first cat of the pair drawn was allocated the LCHP diet, and its pair was automatically assigned the HCLP diet.

During the second phase or stable-weight phase (weeks 5-8), cats were fed for 4 weeks their respective diets to maintain body weight within $95-105 \%$ of their initial weight. Tests to compare the two test diets were performed in the 4th week of feeding (8th week of the study; Table 2).

In the third phase or the weight-gain phase (weeks 9-16), cats were fed their respective diets ad libitum for 8 weeks. In the 9th week (17th week of the study), cats were fed maintenance energetic requirements, and tests were performed to compare the two diets (Table 2).

Food intake was recorded daily and cats were weighed weekly for the duration of the study.

\section{Testing protocol}

General sampling methods. On day 1 of each test week, cats were anaesthetised with alfaxalone (Alfaxan-CD RTU; Jurox Private Limited, Rutherford, NSW, Australia), and a jugular catheter (Arrow International, Reading, PA, USA) was placed percutaneously for blood sampling. Catheter patency was maintained by flushing with a heparinised (Heparin Injection BP; Mayne Pharma Private Limited, Melbourne, VIC, Australia) saline solution (20 IU heparin $/ \mathrm{ml}$ of $0.9 \%$ saline solution) twice daily. This was followed by a dual-energy X-ray absorptiometry scan on day 3 , an insulin-modified intravenous glucose tolerance test on day 5 and a $24 \mathrm{~h}$ mealfeeding test on day 7 . Before each test, cats had food withheld for $24 \mathrm{~h}$. They were fed immediately after each test was concluded. Packed cell volume was monitored, and there were no significant differences before and after each metabolic test, or between tests (data not shown).

\section{Dual-energy $\mathrm{X}$-ray absorptiometry scans}

Total and abdominal fat and lean body masses were measured by dual-energy X-ray absorptiometry with a fan-beam X-ray bone densitometer, using a small animal protocol (Lunar Prodigy, enCORE GE Lunar software platform, version 9.10.108; GE Lunar Incorporation, Madison, WI, USA). Cats were anaesthetised with alfaxalone intravenously, to effect. Whole-body scans were done with cats placed in ventrodorsal recumbency.

Table 2. Timeline of feeding and test weeks

\begin{tabular}{|c|c|c|c|c|c|c|}
\hline Variables & $\begin{array}{l}\text { Baseline-feeding phase } \\
\text { (weeks 1-3) }\end{array}$ & $\begin{array}{l}\text { First test week } \\
\text { (week 4) }\end{array}$ & $\begin{array}{l}\text { Stable-weight phase } \\
\text { (weeks 5-7) }\end{array}$ & $\begin{array}{l}\text { Second test week } \\
\text { (week 8) }\end{array}$ & $\begin{array}{l}\text { Weight-gain phase } \\
\text { (weeks } 9-16 \text { ) }\end{array}$ & $\begin{array}{c}\text { Third test week } \\
\text { (week 17) } \\
\end{array}$ \\
\hline \multicolumn{7}{|l|}{ Group 1} \\
\hline Diet & B & B & LCHP & LCHP & LCHP & LCHP \\
\hline Feeding regimen & $\mathrm{M}$ & $\mathrm{M}$ & M & M & Ad libitum & $\mathrm{M}^{*}$ \\
\hline Cats $(n)$ & 16 & 16 & 15 & 15 & 15 & $14 \dagger$ \\
\hline \multicolumn{7}{|l|}{ Group 2} \\
\hline Diet & B & B & HCLP & HCLP & HCLP & HCLP \\
\hline Feeding regimen & $\mathrm{M}$ & M & M & M & Ad libitum & $M^{*}$ \\
\hline Cats $(n)$ & 16 & 16 & 16 & 16 & 16 & 14 \\
\hline
\end{tabular}

B, baseline; LCHP, low carbohydrate, high protein; M, maintenance; HCLP, high carbohydrate, low protein.

* In the third test week (week 17), cats were fed a restricted amount of food to maintain their weights measured on week 16 within $95-105 \%$.

$\dagger$ Dual-energy X-ray absorptiometry scans were performed in fifteen cats. 


\section{Insulin-modified frequently sampled intravenous glucose} tolerance test with minimal model analysis

Before sampling, $2 \mathrm{ml}$ of blood were removed to clear the catheter of saline-diluted blood. After each sample collection, the saline-diluted blood was re-injected and the catheter flushed with $1 \mathrm{ml}$ of saline solution and $1 \mathrm{ml}$ of heparinised saline solution ( $5 \mathrm{IU}$ heparin/ml of $0.9 \%$ saline solution). The latter was done only when there were $2 \mathrm{~min}$ or more between sample collections.

The test was conducted as described previously ${ }^{(18)}$, except that the sample collected at $20 \mathrm{~min}$ in that study was collected at $19 \mathrm{~min}$ in the present study. Briefly, four baseline blood samples were collected before a glucose (Glucose Injection BP 50\%; Astra Zeneca Proprietary Limited, Sydney, NSW, Australia) bolus of $0.3 \mathrm{~g} / \mathrm{kg}$ was administered intravenously, and twenty-nine blood samples were collected in the subsequent $3 \mathrm{~h}$. At $20 \mathrm{~min}, 0.05 \mathrm{IU}$ regular human insulin $/ \mathrm{kg}$ (Humulin R; Eli Lilly, Sydney, Australia) were injected as a bolus, intravenously. The computer program Minimal Model Millennium (MinMod Millennium, version 6.02; MINMOD Inc., 2001, Los Angeles, CA, USA) was used to determine the insulin sensitivity index and glucose effectiveness based on values obtained from plasma glucose and insulin concentrations at each time point ${ }^{(19)}$.

\section{Meal-feeding test}

Before sampling, $2 \mathrm{ml}$ of blood were removed to clear the catheter of saline-diluted blood. After each sample collection, the saline-diluted blood was re-injected and the catheter flushed with $1 \mathrm{ml}$ of saline solution and $1 \mathrm{ml}$ of heparinised saline solution $(5 \mathrm{IU}$ heparin $/ \mathrm{ml}$ of $0.9 \%$ saline solution or $10 \mathrm{IU}$ heparin $/ \mathrm{ml}$ of $0.9 \%$ saline solution when there were $6 \mathrm{~h}$ between blood sampling).

At 30 and $5 \mathrm{~min}$ before the meal, two fasting blood samples were collected. At time 0 , a meal consisting of $167 \mathrm{~kJ} / \mathrm{kg}$ was fed, and at least $90 \%$ consumed within $30 \mathrm{~min}$. Then, eleven blood samples were collected in the subsequent $24 \mathrm{~h}$, at 1,2 , $3,4,6,8,10,12,15,18$ and $24 \mathrm{~h}$ after the meal was offered. Immediately after collection, blood samples for glucose and insulin analyses were placed into sterile tubes containing EDTA and the proteinase inhibitor aprotinin (Trasylol; Bayer Limited, Sydney, NSW, Australia) at $0.05 \mathrm{ml} / \mathrm{ml}$ of blood collected. Samples were kept on ice for $10-20$ min until centrifuged for $8 \mathrm{~min}$ at $1500 \mathrm{~g}$. After centrifugation, plasma was removed and stored in vials at $-70^{\circ} \mathrm{C}$ until analysis.

Erythrocyte auto-transfusion was performed during this test, to maintain erythrocyte mass as described previously ${ }^{(20)}$. In summary, after plasma was collected, erythrocytes remaining in the EDTA tubes were washed with $0.9 \%$ saline, then resuspended in saline to the initial volume of blood taken and auto-transfused.

\section{Sample analyses}

Plasma glucose was determined using an enzymatic method (Hexokinase enzymatic UV; Olympus Diagnostic Systems
Division, Melville, NY, USA), with mean intra-assay variability of $0.7 \%$, at glucose concentration of $3.3 \mathrm{mmol} / \mathrm{l}$, and $0.5 \%$ at glucose concentrations of 6.3 and $10.4 \mathrm{mmol} / \mathrm{l}$. Mean inter-assay variability was $1 \cdot 3,1 \cdot 0$ and $1 \cdot 1 \%$, respectively. Plasma insulin concentrations were determined by a commercially available RIA kit (Porcine Insulin RIA Kit; Linco Research, Inc., St Charles, MO, USA). The assay has 100\% specificity for human insulin, and was validated for the detection of feline insulin. Assay analytical sensitivity was $12.0 \mathrm{pmol} / 1$. Inter-assay variation was 6.0 and $8.0 \%$ at insulin concentrations of 44.9 and $204.5 \mathrm{pmol} / 1$, respectively. Intraassay variation was $6.5 \%$. Specificity was determined by dilutional parallelism. The standard curves remained parallel to a dilution of $40.0 \%$.

\section{Calculations}

For the $24 \mathrm{~h}$ meal-feeding test, fasting concentrations of glucose and insulin were estimated as the average of concentrations at -30 and $-5 \mathrm{~min}$. Time from the onset of feeding to (1) the time to glucose and insulin concentration first exceed fasting concentration, (2) time to peak concentration and (3) time to return to fasting concentration was calculated based on $90 \%$ ranges of differences using the methodology as described previously ${ }^{(21)}$. For plasma glucose concentration, $90 \%$ ranges of differences were 0.4 and $0.3 \mathrm{mmol} /$ 1 , and those for plasma insulin concentration were 13.2 and $10 \cdot 2 \mathrm{pmol} / 1$ in the second and third test weeks, respectively. Absolute values were used in the calculation of the $90 \%$ ranges of difference for plasma glucose concentration, and ratios of means were used for plasma insulin concentration.

The postprandial period for glucose and insulin was defined as the time from when concentrations first exceeded fasting to the time to return to fasting concentrations.

Peak concentration was defined as the highest concentration observed after feeding, and was defined only for cats that exceeded fasting concentrations as described above.

Mean analyte concentration for $24 \mathrm{~h}$ was calculated as $24 \mathrm{~h}$ area under the curve using the trapezoidal method ${ }^{(22)}$, and then divided by twenty-four.

Energetic efficiency of body-weight gain for the 8 weeks of ad libitum feeding was calculated for each cat as:

\section{(Total energy intake for the 8 weeks of ad libitum feeding \\ - sum of estimated daily energy requirements for the}

8 weeks of ad libitum feeding)/body weight gained.

Total energy intake and body weight gained were calculated from the 8 weeks of ad libitum feeding. Cats were generally weighed weekly. Linear interpolation between consecutive observed weights was used to estimate body weight on days when cats were not weighed. Each cat's daily energy requirement was then calculated for each day

\footnotetext{
(Hexokinase enzymatic UV; Olympus Diagnostic Systems
} 
using the following formula ${ }^{(23,24)}$ :

Daily energy requirement $=151 \cdot 8 \times(\text { body weight }(\mathrm{kg}))^{0 \cdot 40}$

$$
-87 \cdot 5
$$

The constants of 151.8 and 87.5 were determined using daily energy requirements at the end of the $3 \mathrm{rd}$ week of maintenance feeding the baseline or 'washout' diet; body weight was the mean of each cat's daily weight during the 8 weeks of ad libitum feeding; the exponent of 0.40 was used because Earle \& Smith ${ }^{(23)}$ found that the daily energetic requirements/kg body weight decline with higher body weights. The exponent 0.4 removes the effect of weight differences on energy requirements of adult, intact and neutered colony cats ${ }^{(23)}$. Energy efficiency estimates were used only for the twentyeight cats that gained greater than $10 \%$ body weight, as smaller weight gains would have been prone to greater measurement error, since an absolute error when measuring body weight equates to a much larger error when calculating energetic efficiency of body-weight gain if the actual body weight change is small.

Similarly, only cats that gained greater than $10 \%$ body weight were used in the calculation of the percentage of weight gain that was accounted for by each of total and abdominal fat gain. The percentages of weight gain that was accounted for by each of total and abdominal fat gain were calculated as the change in total and abdominal fat masses, respectively, multiplied by 100 and divided by the change in weight from before to after weight gain.

\section{Exclusions}

In the stable-weight phase, one cat was excluded from the study in the second test week (week 8) because a catheter could not be placed in its jugular vein. Therefore, data from the stable-weight phase were analysed for fifteen of the sixteen cats enrolled in the LCHP group, and all sixteen cats enrolled in the HCLP group (Table 2).

During the weight-gain phase, one cat in the LCHP group was not blood sampled because a jugular catheter could not be inserted. Of the cats enrolled in the HCLP group, two were removed from the study at weeks 13 and 16 due to signs (diarrhoea) that indicated dietary intolerance. Data related to body weight, food and energy intake from these cats were included in statistical analyses, also data related to energetic efficiency of weight gain were included for the one of these two cats that had gained at least $10 \%$ in body weight by the time it was removed from the study. During the third test week (week 17), dual-energy X-ray absorptiometry scans were performed in fifteen of the sixteen cats in the LCHP group and in fourteen of the sixteen cats in the HCLP group, and blood was collected from fourteen cats in each dietary group (Table 2).

Data from three cats fed the HCLP diet were not included in the calculation of energetic efficiency, because these cats gained less than $10 \%$ in body weight during the ad libitumfeeding phase (refer to the section Materials and methods, Calculations).

\section{Statistical analyses}

Data were analysed using SigmaStat Version 3.0 (SPSS Incorporation, Chicago, IL, USA) and Stata Version 9.2 (StataCorp LP, College Station, TX, USA). The effects of diet on fasting, peak and mean concentrations of plasma glucose and insulin, on insulin sensitivity and glucose effectiveness were assessed using linear regression with pair fitted as a fixed effect. The individual cat was the unit of analysis. Mean glucose and insulin concentrations were compared between cats fed the LCHP and HCLP diets using linear regression. After inspection of distributions of dependent variables, all were $\log$ (base e)-transformed before analysis to better satisfy the assumptions behind linear regression. After such transformation, exponentiated $\beta$-coefficients for diet from the linear regression models can be interpreted as ratios of geometric means for the two diets.

Comparison between the amount of energy required to maintain body weight between the two test diets during the stable-weight phase was done using linear regression with diet and pair fitted as a fixed effect, without log transformation.

Food and energy intake, and energetic efficiency for weight gain were compared between the diets during the weight-gain phase using linear regression with pair fitted as a fixed effect without log transformation.

Times to first exceeding fasting concentration, times to peak concentration and times to return to fasting concentration for plasma glucose and insulin were compared between the dietary groups using log-rank tests for the equality of Kaplan-Meier survival functions. The individual cat was the unit of analysis. Times to return to fasting concentration were compared only using cats that had exceeding fasting concentration for the same analyte. Times to first exceeding fasting concentration were right-censored at $24 \mathrm{~h}$ for cats not exceeding fasting concentration; similarly, times to peak and to return to fasting concentration were right-censored at $24 \mathrm{~h}$ if peak concentration was not reached, or if concentration did not return to fasting, respectively. Distributions were also compared using Cox, Wilcoxon, Tarone-Ware and Peto-Peto-Prentice tests ${ }^{(25)} . P$ values obtained were similar to those for the log-rank test, and are not reported.

Effects of weight gain on fasting, peak, and mean concentrations of plasma glucose and insulin were assessed by comparing these in cats at the end of the stable-weight phase (when cats were lean) with after the weight-gain phase (when cats were overweight) using linear regression with cat sampling as the unit of analysis, and with body weight status (lean or overweight), diet and cat fitted as fixed effects. Cat was fitted as a fixed effect to account for clustering of residuals due to the repeated measures within cat. Interactions between diet and body weight status were fitted and retained if appropriate. Data were log (base e)-transformed before analysis.

Body weight, lean and fat masses were compared between the ends of the stable-weight (week 8) and weight-gain phases (week 17) using linear regression with cat period as the unit of analysis, and with phase (stable-weight or weight-gain), 
diet and cat fitted as fixed effects, without log transformation. Interactions between diet and test phase were fitted and retained if appropriate.

\section{Results}

\section{Baseline phase}

For all variables measured, mean values were similar between the groups at the end of the baseline phase, after cats were fed for 4 weeks a moderate-carbohydrate baseline or 'washout' diet at maintenance energetic requirements (data not shown).

\section{Body weight, fat and lean masses}

During feeding at maintenance energy requirements (baseline and stable-weight phases), body weights did not vary by more than $5 \%$ from initial body weight for any cat at any stage, and mean body weights were similar ( 3.4 and $3.2 \mathrm{~kg}$ ) in the dietary groups at the end of the stable-weight phase (Table 3 ).

After 8 weeks of ad libitum feeding, mean body weight increase was 37 (range 13-57)\% with the LCHP diet and 17 (range -0.8-36)\% with the HCLP diet (Table 3). Increases for cats in the LCHP group were greater than for cats in the HCLP group; $P$ values for interactions in body weight, total fat, abdominal fat and total lean mass between phase (end of stable-weight or end of weight-gain) and diet were $<0.01$ (Table 3). Body condition scores were on average 6.3/9 for the LCHP group (range 5-7/9), and 5.8/9 for the HCLP group (range 5-7/9).

Of the weight gained in the LCHP group, total fat mass accounted for the majority (61 (SD 14.63)) \%, of which more than one-quarter was abdominal fat (equating to 17

Table 3. Body weight, total and abdominal fat and lean masses measured at the beginning and at the end of the stable-weight phase, and at the end of the weight-gain phase, after 8 weeks of ad libitum feeding

(Mean values, percentages, standard deviations and $95 \%$ confidence intervals)

\begin{tabular}{|c|c|c|c|c|c|c|c|c|c|}
\hline \multirow[b]{2}{*}{ Variables } & \multicolumn{3}{|c|}{ LCHP (n 15) } & \multicolumn{3}{|c|}{ HCLP $(n 16)$} & \multirow[b]{2}{*}{$P \dagger$} & \multirow{2}{*}{$\begin{array}{c}\text { Difference } \ddagger \\
\text { (LCHP relative to } \mathrm{HCLP})\end{array}$} & \multirow[b]{2}{*}{$95 \% \mathrm{Cl}$} \\
\hline & Mean $(\mathrm{kg})$ & $\%^{*}$ & SD & Mean $(\mathrm{kg})$ & $\%^{*}$ & SD & & & \\
\hline \multicolumn{10}{|l|}{ Body weight } \\
\hline \multicolumn{10}{|l|}{ Stable-weight phase } \\
\hline Beginning (week 4) & $3 \cdot 36 \S$ & & 0.76 & $3 \cdot 23$ & & 0.83 & & & \\
\hline \multicolumn{10}{|l|}{ Stable-weight phase } \\
\hline End (week 8) & 3.44 & & 0.73 & $3 \cdot 18$ & & 0.76 & & & \\
\hline \multicolumn{10}{|l|}{ Weight-gain phase } \\
\hline End (week 17) & 4.65 & & 0.88 & $3 \cdot 68$ & & 0.73 & & & \\
\hline Change & $1 \cdot 22$ & & 0.37 & 0.50 & & 0.28 & $<0.01$ & 0.71 & $0.48,0.96$ \\
\hline Range & \multicolumn{3}{|c|}{$1.04-1.39$} & \multicolumn{3}{|c|}{$0.33-0.66$} & & & \\
\hline \multicolumn{10}{|l|}{ Total body fat } \\
\hline \multicolumn{10}{|l|}{ Stable-weight phase } \\
\hline Beginning (week 4) & $0.57 \S$ & 19 & 0.20 & 0.60 & 20 & 0.18 & & & \\
\hline \multicolumn{10}{|l|}{ Stable-weight phase } \\
\hline End (week 8) & 0.57 & 18 & $0 \cdot 18$ & $0.54 \|$ & 19 & 0.15 & & & \\
\hline \multicolumn{10}{|l|}{ Weight-gain phase } \\
\hline End (week 17) & $1 \cdot 31$ & 31 & $0 \cdot 31$ & $0.85 \|$ & 26 & $0 \cdot 16$ & & & \\
\hline Change & 0.74 & 13 & $0 \cdot 26$ & $0.31 \|$ & 7 & 0.17 & $<0.01$ & 0.43 & $0.26,0.59$ \\
\hline Range & \multicolumn{3}{|c|}{$0.63-0.86$} & \multicolumn{3}{|c|}{$0.19-0.43$} & & & \\
\hline \multicolumn{10}{|l|}{ Abdominal fat } \\
\hline \multicolumn{10}{|l|}{ Stable-weight phase } \\
\hline Beginning (week 4) & $0.15 \S$ & 5 & 0.08 & 0.15 & 5 & 0.05 & & & \\
\hline \multicolumn{10}{|l|}{ Stable-weight phase } \\
\hline End (week 8) & 0.13 & 4 & 0.05 & $0 \cdot 12 \|$ & 4 & 0.04 & & & \\
\hline \multicolumn{10}{|l|}{ Weight-gain phase } \\
\hline End (week 17) & 0.34 & 7 & $0 \cdot 10$ & $0 \cdot 20 \|$ & 6 & 0.05 & & & \\
\hline Change & 0.21 & 3 & 0.08 & $0.09 \|$ & 2 & 0.04 & $<0.01$ & 0.12 & $0.07,0.17$ \\
\hline Range & \multicolumn{3}{|c|}{$0.17-0.24$} & \multicolumn{3}{|c|}{$0.05-0.12$} & & & \\
\hline \multicolumn{10}{|l|}{ Total lean mass } \\
\hline Stable-weight phase & & & & & & & & & \\
\hline Beginning (week 4) & $2.57 \S$ & & 0.69 & $2 \cdot 41$ & & 0.67 & & & \\
\hline Stable-weight phase & & & & & & & & & \\
\hline End (week 8) & $2 \cdot 67$ & & 0.66 & $2 \cdot 32 \|$ & & 0.61 & & & \\
\hline Weight-gain phase & & & & & & & & & \\
\hline End (week 17) & 2.90 & & 0.65 & $2 \cdot 39 \|$ & & 0.55 & & & \\
\hline Change & 0.22 & & 0.18 & $0.06 \|$ & & 0.12 & $<0.01$ & 0.16 & $0.04,0.28$ \\
\hline Range & & -0.31 & & - & -0.15 & & & & \\
\hline
\end{tabular}

LCHP, low carbohydrate, high protein; HCLP, high carbohydrate, low protein.

* Percentages calculated in relation to total body mass.

$\dagger P$ value for interaction between lean/overweight and diet.

$\ddagger$ Estimate for the interaction term, i.e. estimated difference in change from lean to overweight between the diets.

$\S n 16$.

|| $n 14$. 
(SD 4.36) \% of body weight gained). Similarly, most (55 (SD 12.62) \% of the weight gained in the HCLP group was due to total fat, of which more than one-quarter was abdominal fat (equating to 15 (SD 5.93)\% of body weight gained; Table 3).

\section{Effects of diet on plasma glucose concentration}

Stable-weight phase. After eating the test diets fed to maintain body weight for 3 weeks, fasting glucose concentration did not differ significantly between the dietary groups $(P=0 \cdot 29)$. However, peak concentration was $24 \%$ or $1.5 \mathrm{mmol} / \mathrm{l}$ higher $(P=0.01)$ and mean concentration was $17 \%$ or $0.9 \mathrm{mmol} / 1$ higher $(P<0.01)$ in cats fed the HCLP diet compared with those fed the LCHP diet (Table 4; Fig. 1(a)). Glucose concentration in two of the fifteen cats (13\%) in the LCHP group did not increase above fasting after the meal, and four of the sixteen cats (25\%) in the HCLP group had not returned to fasting concentration by the end of the meal-feeding test at $24 \mathrm{~h}$ (Table 5). The median times to exceed fasting, to peak and to return to fasting concentration did not differ significantly between the dietary groups ( $P \geq 0 \cdot 08$; Table 5$)$.

Weight-gain phase. After cats had been fed ad libitum for 8 weeks, mean fasting glucose concentration was $7 \%$ or $0.4 \mathrm{mmol} / 1$ lower in cats fed the HCLP diet $(P=0.01)$, mean peak concentration was $27 \%$ or $2.0 \mathrm{mmol} / 1$ higher $(P=0.01)$ and mean concentration over $24 \mathrm{~h}$ was $11 \%$ or $0.64 \mathrm{mmol} / 1$ higher $(P=0.08)$ compared with cats fed the LCHP diet (Table 6; Fig. 1(b)). Whereas glucose had returned to fasting concentration by the end of the meal-feeding test in all cats in the HCLP group, in four of the fourteen cats (28\%) in the LCHP group, it was still significantly above fasting by the end of the $24 \mathrm{~h}$ test (Table 7 ). The increase in glucose concentration after eating occurred earlier in cats fed the HCLP diet than in cats fed the LCHP $\operatorname{diet}(P=0 \cdot 01$; Table 7). Median times to peak and times to return to fasting concentration did not differ significantly between the dietary groups ( $P \geq 0 \cdot 74$; Table 7).

Effects of weight gain on plasma glucose concentration (comparison between the end of the stable-weight phase and the end of the weight-gain phase). Compared with when cats were lean at the end of the stable-weight phase, $24 \mathrm{~h}$ mean glucose concentration increased significantly after a mean weight gain of $37 \%$ in cats consuming the LCHP diet, but did not increase significantly after a mean weight gain of $17 \%$ in cats fed the HCLP diet (Tables 4 and 6; Fig. 1(a) and (b)).

Compared with when cats were lean, after weight gain, mean fasting concentration was $0.1 \mathrm{mmol} / 1$ higher in cats fed the LCHP diet and $0.4 \mathrm{mmol} / 1$ lower in cats fed the HCLP diet. This change in fasting glucose concentration from when cats were lean to when they were overweight was NS for cats fed the LCHP diet (estimated change 2\%; 95\% CI $-4,9 \% ; P=0.44)$, but was significant after weight gain in cats fed the HCLP diet (estimated change 8\% lower; 95\% CI 2, $13 \%$ lower; $P=0.01$; significance of interaction $P=0.02$ ). Peak glucose concentration was significantly higher after 
(a)

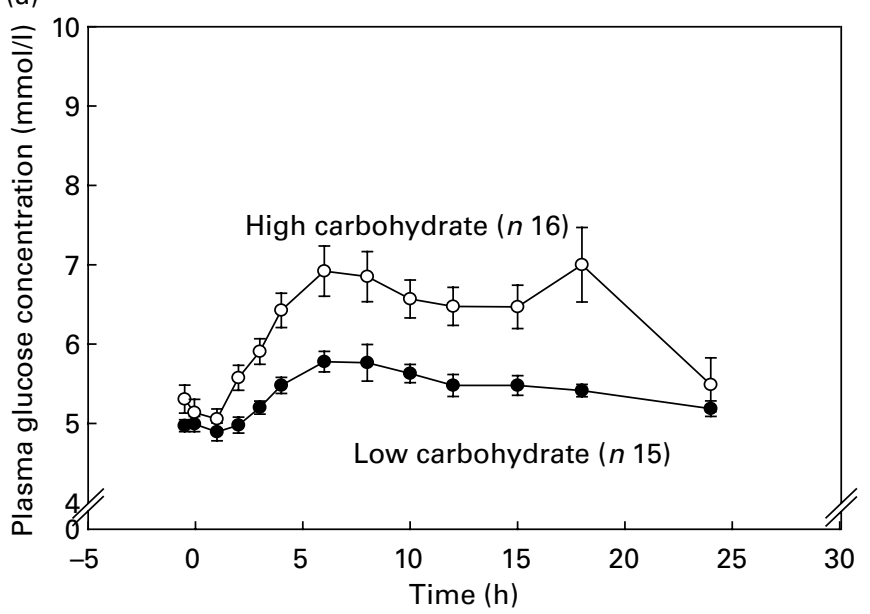

(b)

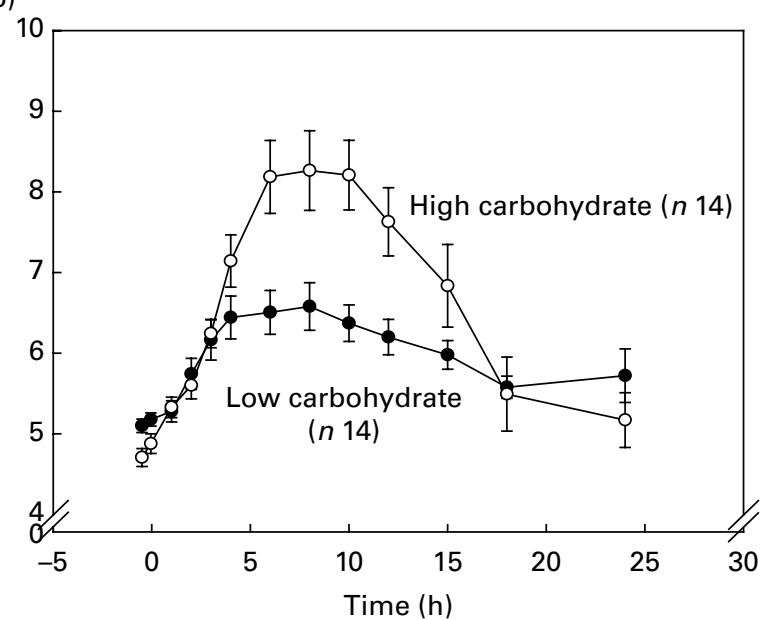

Fig. 1. Comparison of the changes in plasma glucose concentration in the low carbohydrate, high protein $(\bullet)$ and high carbohydrate, low protein $(O)$ dietary groups before and after weight gain. (a) End of stable-weight phase and (b) end of weight-gain phase. Values are means, with standard errors of the mean represented by vertical bars.

weight gain relative to when cats were lean in both dietary groups. Peak glucose increased by $1.2 \mathrm{mmol} / \mathrm{l}$ (estimated change $18 \% ; 95 \%$ CI 10, 28\%; $P<0.01)$. There was no evidence of interaction between phase (end of stable-weight or end of weight-gain) and diet ( $P$ for interaction=0.99). Compared with when cats were lean, mean glucose concentration was $11 \%$ or $0.6 \mathrm{mmol} / \mathrm{l}$ higher after a mean weight gain of $37 \%$ in cats fed the LCHP diet (95\% CI 5, 18\%; $P<0.01$ ), but did not change significantly with a mean weight gain of $17 \%$ in cats fed the HCLP diet (mean glucose concentration $0.2 \mathrm{mmol} / 1$ lower; estimated change 3\%; $95 \%$ CI $-3,9 \% ; P=0.36$ ). The $P$ value for the interaction term was $0 \cdot 05$.

In lean cats fed the HCLP diet, mean plasma glucose concentration over $24 \mathrm{~h}$ did not differ significantly from cats fed the LCHP diet at the end of the weight-gain phase, which had gained an average of $37 \%$ body weight (Fig. 1(a) and (b)). The estimated percentage difference between lean cats fed the HCLP diet relative to cats after weight gain in the ad libitum-feeding phase that were fed the LCHP diet was 5\% higher (95\% CI $-4,16 \% ; P=0 \cdot 20)$.

\section{Effects of diet on plasma insulin concentration}

Stable-weight phase. Similar to glucose, fasting insulin concentration did not differ between the dietary groups after eating their respective diets, maintaining a lean body weight $(P=0 \cdot 37)$. Peak concentration was $59 \%$ or $64 \cdot 1 \mathrm{pmol} / 1$ higher $(P<0.01)$ and mean concentration was $36 \%$ or $24.7 \mathrm{pmol} / 1$ higher $(P=0.03)$ in cats fed the HCLP diet compared with cats fed the LCHP diet (Table 4; Fig. 2(a)). Plasma insulin concentration in two of the fifteen cats in the LCHP group (13\%) did not increase above fasting in the postprandial period (Tables 4 and 5).

Table 5. Times $(\mathrm{h})$ to exceed fasting concentration, times to peak and times to return to fasting concentration for plasma glucose and insulin during the $24 \mathrm{~h}$ meal-feeding test at the end of the stable-weight phase, after lean cats had been fed either the low carbohydrate, high protein or the high carbohydrate, low protein diet maintaining their body weight for 3 weeks

(25th percentiles, median values, 75 th percentiles)

\begin{tabular}{|c|c|c|c|c|c|c|c|}
\hline \multirow[b]{2}{*}{ Variables } & \multicolumn{3}{|c|}{ LCHP (n 15) } & \multicolumn{3}{|c|}{ HCLP $(n 16)$} & \multirow{2}{*}{$\begin{array}{c}P \text { for difference } \\
\text { between the groups }\end{array}$} \\
\hline & $25 \%$ & Median & $75 \%$ & $25 \%$ & Median & $75 \%$ & \\
\hline \multicolumn{8}{|l|}{ Glucose } \\
\hline First time to exceed fasting concentration & 1.9 & $3 \cdot 3$ & 4.5 & 1.5 & 1.8 & 3.6 & 0.08 \\
\hline Time to peak & $6 \cdot 0$ & $8 \cdot 0$ & $10 \cdot 0$ & $6 \cdot 0$ & $10 \cdot 0$ & $15 \cdot 8$ & 0.83 \\
\hline Time to return to fasting concentration* ${ }^{*}$ & 11.4 & $17 \cdot 6$ & 19.5 & $15 \cdot 8$ & $19 \cdot 8$ & $-t$ & 0.18 \\
\hline \multicolumn{8}{|l|}{ Insulin } \\
\hline First time to exceed fasting concentration & 0.6 & 0.7 & 0.9 & 1.0 & 1.5 & $2 \cdot 1$ & 0.37 \\
\hline Time to peak & 1.0 & $4 \cdot 0$ & 8.0 & $2 \cdot 8$ & $5 \cdot 0$ & 8.0 & 0.29 \\
\hline Time to return to fasting concentrations ${ }^{*}$ & $3 \cdot 0$ & $8 \cdot 1$ & $15 \cdot 5$ & 9.5 & $12 \cdot 8$ & $18 \cdot 2$ & 0.38 \\
\hline
\end{tabular}

LCHP, low carbohydrate, high protein; HCLP, high carbohydrate, low protein.

* Calculated only for the thirteen cats in the LCHP group and the sixteen cats in the HCLP group whose concentrations increased significantly above fasting during the $24 \mathrm{~h}$ meal-feeding test.

† Could not be calculated as not more than $75 \%$ of cats had returned to fasting concentration by the end of observations at $24 \mathrm{~h}$. 
Table 6. Fasting, peak and mean concentrations of plasma glucose and insulin during a $24 \mathrm{~h}$ meal-feeding test, insulin sensitivity and glucose effectiveness based on the minimal model analysis of the insulin-modified intravenous glucose tolerance test at the end of the weight-gain phase, after cats had been fed a low carbohydrate, high protein or high carbohydrate, low protein diet ad libitum for 8 weeks

(Mean values, standard deviations, ranges and $95 \%$ confidence intervals)

\begin{tabular}{|c|c|c|c|c|c|c|c|c|c|}
\hline \multirow[b]{3}{*}{ Variables } & \multicolumn{6}{|c|}{ Diet } & \multirow[b]{3}{*}{$P$} & \multirow{3}{*}{$\begin{array}{l}\text { Ratio of means } \\
\text { (LCHP:HCLP)* }\end{array}$} & \multirow[b]{3}{*}{$95 \% \mathrm{Cl}$} \\
\hline & \multicolumn{3}{|c|}{$\mathrm{LCHP}(n 12)$} & \multicolumn{3}{|c|}{$\operatorname{HCLP}(n 12)$} & & & \\
\hline & Mean† & SD & Range & Meant & SD & Range & & & \\
\hline \multicolumn{10}{|l|}{ Glucose $(\mathrm{mmol} / \mathrm{l})$} \\
\hline Fasting & $5 \cdot 2$ & 0.3 & $4 \cdot 6-5 \cdot 6$ & 4.8 & 0.4 & $4 \cdot 2-6 \cdot 0$ & 0.01 & 1.07 & $1.03,1.12$ \\
\hline Peak & $7 \cdot 2$ & $1 \cdot 3$ & $5 \cdot 6-9 \cdot 9$ & $9 \cdot 2$ & 1.9 & $6 \cdot 6-13 \cdot 4$ & 0.01 & 0.79 & $0.67,0.93$ \\
\hline Mean & $6 \cdot 0$ & 0.6 & $5 \cdot 1-7 \cdot 0$ & $6 \cdot 6$ & 1.0 & $5 \cdot 3-9 \cdot 0$ & 0.08 & 0.90 & $0.80,1.02$ \\
\hline \multicolumn{10}{|l|}{ Insulin (pmol/l) } \\
\hline Fasting & 44.5 & $13 \cdot 1$ & $25 \cdot 6-69 \cdot 1$ & $32 \cdot 2$ & $15 \cdot 5$ & $13 \cdot 7-71 \cdot 6$ & 0.12 & 1.38 & $0.91,2 \cdot 10$ \\
\hline Peak & $175 \cdot 1$ & $44 \cdot 2$ & $134.6-289.9$ & $176 \cdot 8$ & $65 \cdot 3$ & $105 \cdot 2-328 \cdot 9$ & 0.94 & 0.99 & $0.74,1.32$ \\
\hline Mean & $97 \cdot 7$ & $18 \cdot 4$ & $71 \cdot 0-145 \cdot 5$ & $93 \cdot 8$ & $44 \cdot 6$ & $59 \cdot 2-207 \cdot 5$ & 0.79 & 1.04 & $0.75,1.45$ \\
\hline Insulin sensitivity $\left((\mu \mathrm{U} / \mathrm{l})^{-1} \mathrm{~min}^{-1}\right)$ & 2.54 & 1.37 & $1 \cdot 13-5 \cdot 64$ & $2 \cdot 41$ & 1.77 & $0.56-5.29$ & 0.84 & 1.05 & $0.62,1.77$ \\
\hline Glucose effectiveness $\left(\min ^{-1}\right)$ & 0.02 & 0.01 & $0-0.03$ & 0.03 & 0.01 & $0.01-0.05$ & 0.04 & 0.63 & $0.41,0.98$ \\
\hline
\end{tabular}

LCHP, low carbohydrate, high protein; HCLP, high carbohydrate, low protein.

${ }^{*}$ Ratio of means (LCHP:HCLP), adjusted for pair.

$\dagger$ Concentrations are reported as geometric means. Values have been reported only for cats from pairs in which both cats were tested; within each pair, one cat was allocated to each dietary group.

Weight-gain phase. After cats had been fed ad libitum for 8 weeks, fasting, peak and mean plasma insulin concentrations were not significantly different between the two dietary groups $(P \geq 0 \cdot 12$; Table 6 ; Fig. 2(b)). Similarly, the median times to exceed fasting, to peak and to return to fasting concentrations were not significantly different between the groups ( $P \geq 0 \cdot 30$; Table 7; Fig. 2(b)).

Effects of weight gain on plasma insulin concentration (comparison between the end of the stable-weight phase and the end of the weight-gain phase). In general, compared with when cats were lean at the end of the stableweight phase, fasting, peak and mean insulin concentrations increased significantly after a mean weight gain of $37 \%$ in cats consuming the LCHP diet, but did not increase significantly after a mean weight gain of $17 \%$ in cats fed the HCLP diet (Tables 4 and 6; Fig. 2(a) and (b)).

Fasting insulin concentration increased $43 \%$ or $13.8 \mathrm{pmol} / 1$ after weight gain in cats fed the LCHP diet (95\% CI 15, $79 \% ; P<0.01)$ and was $22 \%$ or $8.4 \mathrm{pmol} / 1$ lower after weight gain in cats fed the HCLP diet (95\% CI 2, 37\% lower; $P=0.03$; significance of interaction $P<0.01)$. Peak insulin concentration was $48 \%$ or $64.2 \mathrm{pmol} / 1$ higher after weight gain in cats fed the LCHP diet (95\% CI 24, 78\%; $P<0.01)$, but did not change significantly (mean peak was $0.6 \mathrm{pmol} / 1$ lower) after weight gain in cats fed the HCLP diet (estimated change $0 \% ; 95 \%$ CI $-16,18 \% ; P=0.96$; significance of interaction $P<0 \cdot 01)$. Mean insulin concentration increased $46 \%$ or $31.2 \mathrm{pmol} / 1$ after weight gain in cats fed the LCHP diet (95\% CI 25, 71\%; $P<0.01$ ), but did not change significantly (mean concentration was $2.4 \mathrm{pmol} / 1$ lower) with weight gain in cats fed the HCLP diet (estimated change $2 \%$; $95 \%$ CI $-17, \quad 15 \% ; P=0.77$; significance of interaction $P<0 \cdot 01)$.

Although mean insulin concentration increased $46 \%$ with an average of $37 \%$ weight gain in cats fed the LCHP diet, the HCLP diet in lean cats resulted in similar mean plasma insulin concentration compared with cats fed the LCHP diet after weight gain (Tables 4 and 6; Fig. 2(a) and (b)). Estimated

Table 7. Times to exceed fasting concentration, times to peak and times to return to fasting concentration for plasma glucose and insulin during the $24 \mathrm{~h}$ meal-feeding test at the end of the weight-gain phase, after cats had been fed the low carbohydrate, high protein or the high carbohydrate, low protein diet ad libitum for 8 weeks

(25th percentiles, median values, 75th percentiles)

\begin{tabular}{|c|c|c|c|c|c|c|c|}
\hline \multirow[b]{2}{*}{ Variables } & \multicolumn{3}{|c|}{ LCHP (n 14) } & \multicolumn{3}{|c|}{ HCLP $(n 14)$} & \multirow{2}{*}{$\begin{array}{c}P \text { for difference } \\
\text { between the groups }\end{array}$} \\
\hline & $25 \%$ & Median & $75 \%$ & $25 \%$ & Median & $75 \%$ & \\
\hline \multicolumn{8}{|l|}{ Glucose } \\
\hline First time to exceed fasting concentration & 0.80 & $1 \cdot 8$ & $2 \cdot 8$ & 0.40 & $0 \cdot 70$ & 1.5 & 0.01 \\
\hline Time to peak & $6 \cdot 5$ & $8 \cdot 0$ & $10 \cdot 0$ & $6 \cdot 0$ & $9 \cdot 0$ & $12 \cdot 0$ & 0.85 \\
\hline $\begin{array}{l}\text { Time to return to fasting concentration } \\
\text { Insulin }\end{array}$ & $10 \cdot 4$ & $16 \cdot 6$ & $-^{*}$ & $14 \cdot 2$ & $17 \cdot 1$ & $18 \cdot 6$ & 0.74 \\
\hline First time to exceed fasting concentration & 0.3 & 0.6 & 0.6 & 0.2 & 0.3 & 1.5 & 0.30 \\
\hline Time to peak & $1 \cdot 0$ & $4 \cdot 0$ & $8 \cdot 0$ & $6 \cdot 0$ & $8 \cdot 0$ & $12 \cdot 0$ & 0.08 \\
\hline Time to return to fasting concentration & $9 \cdot 6$ & $14 \cdot 1$ & $17 \cdot 5$ & $13 \cdot 1$ & $16 \cdot 4$ & $18 \cdot 5$ & 0.70 \\
\hline
\end{tabular}

LCHP, low carbohydrate, high protein; HCLP, high carbohydrate, low protein.

${ }^{*}$ Could not be calculated as not more than $75 \%$ of cats had returned to fasting concentration by the end of observations at $24 \mathrm{~h}$. 

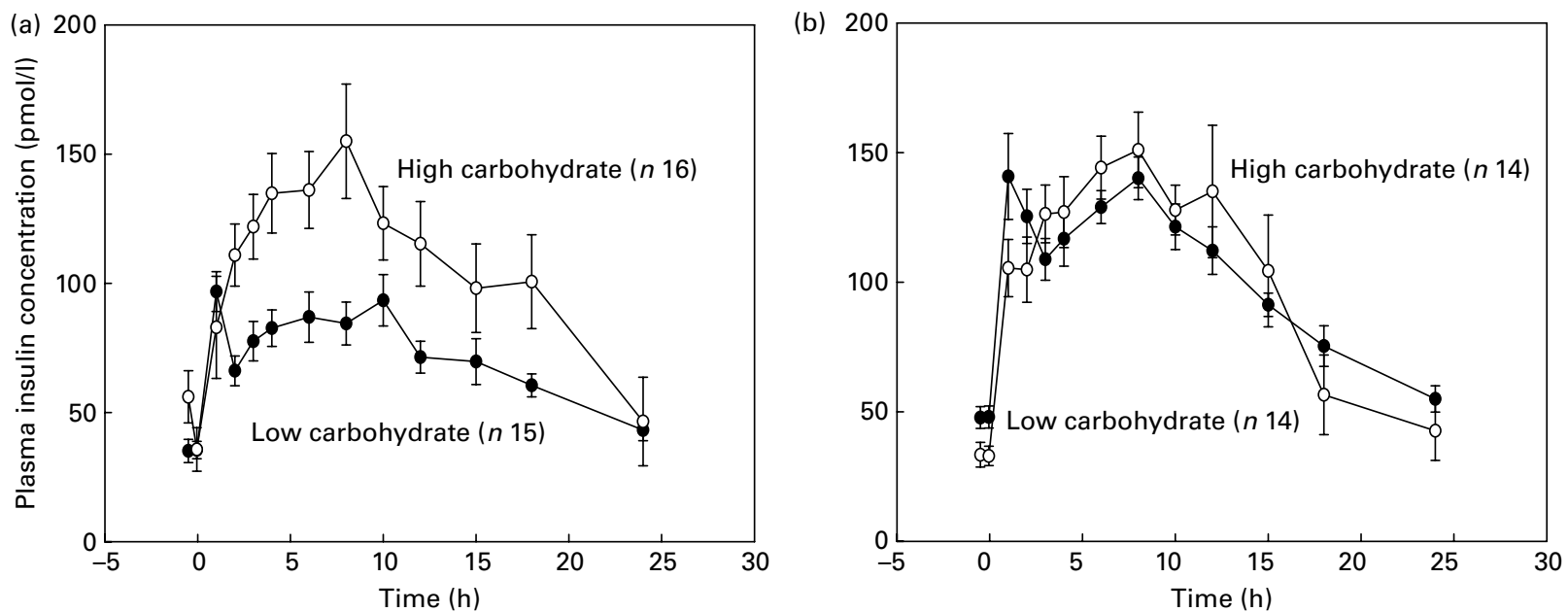

Fig. 2. Comparison of the changes in plasma insulin concentration in the low carbohydrate, high protein $(\bullet)$ and high carbohydrate, low protein $(O)$ dietary groups

before and after weight gain. (a) End of stable-weight phase and (b) end of weight-gain phase. Values are means, with standard errors of the mean represented by vertical bars.

percentage difference in lean cats fed the HCLP diet relative to cats after $37 \%$ mean weigh gain fed the LCHP diet was $5 \%$ lower (95\% CI $-29,26 \% ; P=0 \cdot 70)$.

\section{Effects of diet on insulin sensitivity and glucose effectiveness}

Insulin sensitivity did not differ significantly between the diets either when cats were lean $(P=0.39)$ or after weight gain ( $P=0.84$; Tables 4 and 6 ). Insulin sensitivity did not change significantly with weight gain $(P=0.90)$, and there was no significant interaction between phase and diet $(P=0 \cdot 23)$.

There was no significant difference in glucose effectiveness between the diets when cats were lean $(P=0 \cdot 85)$; however, glucose effectiveness was significantly higher after weight gain in cats fed the HCLP diet compared with cats fed the LCHP diet ( $P=0 \cdot 04$; Tables 4 and 6). Glucose effectiveness increased significantly with weight gain $(P=0.03)$. There was no significant interaction between phase and diet $(P=0.77)$.

\section{Energetic efficiency of weight gain}

The amount of energy required to maintain the body weight within 95-105\% of initial weight during the stable-weight phase was significantly less for cats fed the LCHP diet compared with cats fed the HCLP diet. Cats fed the LCHP diet ate on average $2.24 \mathrm{~g}$ less of food $/ \mathrm{kg}$ body weight per $\mathrm{d}$ than cats fed the HCLP diet (95\% CI 0.39, 4.09; $P=0.02$ ), equivalent to $41.8 \mathrm{~kJ} / \mathrm{kg}$ body weight per d less energy $(95 \%$ CI $16 \cdot 0,67 \cdot 6 ; P<0 \cdot 01$ ). Energy intake averaged $178 \cdot 1 \mathrm{~kJ} / \mathrm{kg}$ body weight per $\mathrm{d}$ for the LCHP diet and $220 \cdot 2 \mathrm{~kJ} / \mathrm{kg}$ body weight per $\mathrm{d}$ for the HCLP diet.

In the weight-gain phase of the study, over 8 weeks of ad libitum feeding, the average food and energy intakes were similar in both groups. Food and energy intakes were $24 \mathrm{~g} / \mathrm{kg}$ per $\mathrm{d}$ and $318 \mathrm{~kJ} / \mathrm{kg}$ per $\mathrm{d}$ in the LCHP group, and $25 \mathrm{~g} / \mathrm{kg}$ per $\mathrm{d}$ and $346 \mathrm{~kJ} / \mathrm{kg}$ per $\mathrm{d}$ in the HCLP group of cats. Cats fed the LCHP diet ate on average $0.73 \mathrm{~g}$ of food less/kg body weight per $\mathrm{d}$ than cats fed the HCLP diet, a difference which was not significant (95\% CI - 3.39, 4.86; $P=0.71)$. Similarly, cats fed the LCHP diet consumed on average $31 \cdot 8 \mathrm{~kJ} / \mathrm{kg}$ body weight per $\mathrm{d}$ less than cats fed the HCLP diet (95\% CI $-26 \cdot 30,89 \cdot 84 ; P=0 \cdot 26$ ).

The LCHP diet resulted in greater energetic efficiency for body-weight gain: mean values were $52845 \mathrm{~kJ} / \mathrm{kg}$ weight gain $v .100377 \mathrm{~kJ} / \mathrm{kg}$ weight gain for the LCHP and HCLP diets, respectively. Cats fed the LCHP diet required on average $34696 \mathrm{~kJ}$ less to gain $1 \mathrm{~kg}$ in body weight than cats fed the HCLP diet (95\% CI 19663, $49728 ; P<0 \cdot 01$ ).

During the weight-gain phase, when food intake increased by $57 \%$, thirteen out of the sixteen cats ( $81 \%$ ) fed the HCLP diet developed diarrhoea. Faecal tests of some cats for parasites and potentially pathogenic bacteria were negative, and the diarrhoea did not resolve despite feeding a new batch of food and changing the source of protein from poultry to beef. Of these cats with diarrhoea, two cats that had constant watery diarrhoea were removed from the study. In all cats with diarrhoea, including the cats that were removed from the study, the diarrhoea resolved within $24 \mathrm{~h}$ after commencement of feeding the LCHP diet ad libitum.

\section{Discussion}

Based on the present results, there were a number of noteworthy findings. First, when fed ad libitum, a LCHP diet resulted in greater weight gain than a HCLP diet. This is in agreement with a previous study that evaluated the effect on weight gain in gonadectomised cats of low- and highcarbohydrate diets with similar amounts of protein and varying in fat content. In that study, weight gain after 17 weeks of ad libitum feeding was significantly higher in cats fed diets lower in carbohydrate (3 and 22\% ME) and higher in fat (64 and 44\% ME, respectively) compared with cats fed diets with high ( $57 \% \mathrm{ME}$ ) and moderate ( $41 \% \mathrm{ME})$ carbohydrate content and lower in fat $(9$ and $25 \% \mathrm{ME}$, respectively) ${ }^{(14)}$. In fact, weight gain increased linearly with dietary fat content $(\% \mathrm{ME})^{(14)}$. However, the lowest carbohydrate 
diet had $90 \%$ greater energy density than the highest, confounding the findings. The energy densities of the diets used in the present study were similar. Therefore, the present results increase confidence that when fed ad libitum, LCHP diets result in greater weight gain compared with HCLP diets, even when diets are of comparable energy density.

We hypothesise that the lower weight gain associated with the HCLP diet might result from several factors. First, although the energy densities were similar, the proportion of energy from fat was slightly lower in the HCLP diet (28v. 30\% ME). Second, cats are reported to limit their carbohydrate intake, and this 'ceiling' effect on carbohydrate intake might have limited body-weight gain in our high-carbohydrate-fed cats ${ }^{(26)}$. However, in the ad libitum phase, the cats in the present study consumed amounts of carbohydrate twice that reported for the carbohydrate ceiling in cats (mean $624 v$. $300 \mathrm{~kJ} / \mathrm{d}$ ). It is possible that this higher carbohydrate intake in our cats reflects a longer adaptation period (12 weeks in the present study $v$. 1 week in the reported study) and/or the need to meet minimum protein requirements. A third hypothesis for the lower weight gain is that the energy bioavailability of the HCLP diet was substantially less than that of the LCHP diet. Loose stools were observed in the majority of cats given the HCLP diet during the weight-gain phase, and this might indicate there was fermentation of substrate that otherwise should have been available for absorption and utilisation of energy.

An important finding from the study was that the greater weight gain occurred because of greater energy efficiency associated with the LCHP diet. Cats eating the LCHP diet required significantly less energy $(\mathrm{kJ} / \mathrm{kg})$ to maintain their body weight when fed at maintenance energy requirements, and their energetic efficiency for body-weight gain was higher. The finding that when fed ad libitum, cats in the LCHP group consumed a similar amount of energy $/ \mathrm{kg}$ body weight per $d$ to cats eating the HCLP diet, but gained more weight, is in contrast to findings in human subjects where LCHP diets (Atkins diets) are associated with reduced energy intake and subsequently greater weight loss than high-carbohydrate diets ${ }^{(27)}$. The findings in the present study are unlikely to be the result of marginal protein content in the HCLP diet because lean mass as measured by dualenergy X-ray absorptiometry did not change significantly from baseline at any time point over the 3 months (mean total lean mass was $2.4 \mathrm{~kg}$ before and after consuming the HCLP diet for 12 weeks).

Notably in the present study, $81 \%$ of cats fed the HCLP diet ad libitum developed diarrhoea, suggesting that feeding excessive quantities of starch is not well tolerated in cats. Dietary carbohydrate has been reported to cause gastrointestinal disturbances in cats due to its osmotic effect if the amount eaten exceeds the digestive capacity of the small intestine ${ }^{(3,28)}$, which has been reported to occur when carbohydrate content exceeds $40 \%$ on a DM basis ${ }^{(29)}$. The National Research Council (USA) considers the adverse effects of carbohydrate in cats to include loose stools, elevated faecal water content and frequent defaecation ${ }^{(30)}$. The findings in the present study are consistent with faecal quality data provided by the manufacturer from a digestibility trial following the Association of American Feed Control Officials' guidelines using the same high-carbohydrate diet used in the present study. At maintenance energy requirements, six adult cats (aged 1-8 years) were fed the HCLP diet and consumed $97 \%$ of the amount offered. Faecal quality was poor based on $37.5 \%$ unacceptable faeces, consisting of loose stools and diarrhoea with only $2 \cdot 8 \%$ ideal faeces. The carbohydrate source of the HCLP diet used in the present study was mainly wheat starch. However, it is unlikely that the wheat contributed to diarrhoea, because faecal quality data provided by the manufacturer for the same diet as the baseline diet (carbohydrate $37 \% \mathrm{ME}$ ), but with wheat as the carbohydrate source, were associated with $0 \%$ of unacceptable faeces. As both diets in the present study had very similar apparent digestibility scores, poor total digestibility of the HCLP diet does not explain the diarrhoea. However, it should be noted that apparent digestibility measures total intestinal tract digestibility and represents the combination of starch digested by mammalian enzymes and digestion of undigested starch in the colon by bacteria.

Previous studies have shown that cats are not adapted to use carbohydrate efficiently as a source of energy ${ }^{(28)}$. Cats lack salivary amylase ${ }^{(31)}$ and have low activity of intestinal enzymes that break down carbohydrates, such as intestinal amylase, and disaccharidases ${ }^{(2,4,32)}$. When fed at maintenance energy requirements, the HCLP diet did not cause diarrhoea; intolerance was only clinically evident during ad libitum feeding when the amount of carbohydrate eaten daily increased by $57 \%$. The resultant diarrhoea has been reported to be generally associated with the low activity of primary or secondary disaccharidases in cats ${ }^{(29)}$. Clinically, this may only be seen in cats being fed a high-carbohydrate diet and eating to excess during a rapid weight-gain phase, for example after neutering or in a newly adopted underweight cat, and would be expected to resolve over time as food intake stabilises towards maintenance levels.

A second finding is that most of the additional energy consumed by cats in both dietary groups during the ad libitum feeding resulted in increased fat deposition, which was predominantly external to the abdomen and presumably subcutaneous fat. This is in agreement with a previous study that evaluated the effect of diets of different composition on fat mass in gonadectomised cats ${ }^{(33)}$. In the present study, total lean mass also increased with weight gain in the LCHP group. The increase in lean mass occurred in smaller proportion relative to the proportional increase in fat mass, which is in agreement with previous findings in human subjects that fat mass and lean mass change in the same direction as weight changes, with fat mass being more responsive to weight change than lean mass ${ }^{(34,35)}$

Third, in contrast to the adverse effects on body weight of feeding a LCHP diet ad libitum, if fed at maintenance energy requirements, a LCHP diet might be beneficial for cats with a combination of risk factors for diabetes such as aged, obese, male cats, because of the smaller increase in plasma glucose and insulin concentrations after a meal compared with cats fed a HCLP diet. The present results 
demonstrated that in lean cats, the LCHP diet results in lower mean and peak glucose and insulin concentrations for at least $18 \mathrm{~h}$ after eating compared with the HCLP diet. This is in agreement with results from a recent study in cats fed a diet with $41 \mathrm{~g} / 100 \mathrm{~g}$ carbohydrate compared with diets with lower amounts of carbohydrate $(31 \text { and } 21 \mathrm{~g} / 100 \mathrm{~g})^{(7)}$. Nevertheless, in the present study, to maintain the energy content of the diets when the carbohydrate content of the diet was changed, a compensatory change in protein was made. The observed effects on postprandial plasma glucose and insulin concentrations could be due to changes in protein content, because amino acids stimulate insulin secretion and are a substrate for gluconeogenesis ${ }^{(36,37)}$. However, results from studies in human subjects, cats and dogs indicate that carbohydrates are the principal nutrients involved in the postprandial changes in plasma glucose and insulin ${ }^{(7,38,39)}$.

Carbohydrate source might have had some influence on postprandial glucose and insulin concentrations in the present study. The difference between rice and maize/sorghum as carbohydrate sources has been previously shown to have only minor effects on postprandial blood glucose concentration, compared with the marked effect resulting from differences in the total amount of carbohydrate (Farrow HA, Rand JS and Sunvold GD (2002), unpublished results) ${ }^{(7,40)}$. However, a recent study of novel carbohydrate sources such as lentil and cassava flour demonstrated that the glucose and insulin increase after eating is minimum compared with $\operatorname{corn}^{(41)}$, which was the carbohydrate source used in the LCHP diet in the present study. The HCLP diet used in the present study had wheat as the carbohydrate source, and there are no data in cats demonstrating the glycaemic response to wheat. It is possible that wheat results in a higher postprandial glycaemic response than maize and that might also have contributed to the magnitude of increase in glucose and insulin in the HCLP diet.

A fourth finding was that after an average weight gain of $37 \%$, cats eating the LCHP diet had a similar mean glucose concentration over $24 \mathrm{~h}$ as lean cats eating the HCLP diet. This suggests that a HCLP diet produces similar adverse effects on mean postprandial glucose concentrations to the effects of a substantial short-term weight gain. Of more concern with respect to the potential to predispose to diabetes, the HCLP diet in lean cats resulted in similar mean plasma insulin concentration for at least $15 \mathrm{~h}$ after eating compared with the postprandial increase in insulin concentration associated with a mean $37 \%$ weight gain in cats eating a LCHP diet. Chronic hyperglycaemia increases the demand on the $\beta$-cells to secrete insulin, and chronic hyperinsulinaemia is associated with eventual $\beta$-cell failure and type 2 diabetes ${ }^{(15)}$ The International Diabetes Federation defines postprandial hyperglycaemia in humans as a plasma glucose concentration of greater than $7.8 \mathrm{mmol} / \mathrm{l}^{(42)}$, and individual cats in the present study fed the HCLP diet had mean glucose concentrations above this level. This suggests that if fed long-term, highcarbohydrate diets could potentially predispose to type 2 diabetes in susceptible cats, that is, cats with underlying low insulin sensitivity, for example aged, obese or Burmese cats, or those with underlying loss of $\beta$-cells from islet amyloid deposition.

In a study of feline patients in the UK, consumption of wet diets (lower in carbohydrate) and dry diets (higher in carbohydrate) were both associated with greater risk for diabetes compared with a mixed diet containing both wet and dry foods ${ }^{(43)}$. Cats fed wet diets were three times more likely to develop diabetes than cats fed mixed diets; cats fed dry diets had two times the risk. This is consistent with the findings from the present study, because both weight gain and consumption of a HCLP diet were associated with higher mean glucose and insulin concentrations over $24 \mathrm{~h}$ compared with glucose and insulin concentrations in lean cats fed the LCHP diet. Based on the results of the UK study, it has been suggested that the adverse effects of obesity resulting from ad libitum feeding of low-carbohydrate diets (higher in fat) and the adverse effects of chronically higher demand for insulin secretion resulting from feeding high-carbohydrate diets both predispose to diabetes, with the obesity-potentiating effect posing greater risk. To further investigate the role of diet in predisposing to feline diabetes, additional well-designed dietary studies are required in which the confounding effects of ad libitum feeding and obesity have been controlled for, and sufficient numbers of cats are enrolled to have the statistical power to detect differences if they were present.

Insulin sensitivity was not different between diets or between lean and overweight cats. Insulin sensitivity is measured in the fasted state, which might minimise a dietary effect if present. Currently, there are no methods available to measure insulin sensitivity in the postprandial state. It is possible that moderate (26 and 31\% total body fat), short-term weight gain ( 8 weeks in the present study) may have different effects on insulin sensitivity to more pronounced weight gain over a longer period. In contrast to the present study where none of the cats were classed as obese, insulin sensitivity was halved when cats became obese over 10 months ${ }^{(13)}$. It is also possible that because most of the fat gained was outside the abdomen, it might have diminished the effect on insulin sensitivity ${ }^{(44,45)}$.

Glucose effectiveness measures the ability of glucose per se, under basal insulin conditions, to promote its own disposal through mass action into tissues and suppress endogenous glucose production ${ }^{(46,47)}$. In healthy human subjects, $50 \%$ of the glucose disposal during a glucose tolerance test is due to glucose effectiveness ${ }^{(47)}$. Glucose effectiveness is enhanced with increased plasma insulin or glucose concentrations, and a 4-fold increase in insulin or a doubling of glucose concentrations result in a similar enhancing effect ${ }^{(47,48)}$. Although glucose effectiveness was not significantly different between the diets during the stable-weight phase, it increased with weight gain, and was significantly higher in cats fed the HCLP diet. Because insulin concentrations were not different between the diets after weight gain, but peak glucose concentration was significantly higher in cats fed the HCLP diet, it suggests that the higher glucose effectiveness with weight gain reflected the higher glucose concentration (mean peak $7 \cdot 2$ v. $9 \cdot 2 \mathrm{mmol} / \mathrm{l}$ ). The lower fasting glucose concentration 
in the HCLP group after weight gain might reflect increased glucose effectiveness.

Limitations of the study were that the diets were commercially available diets which had other micronutrient differences between them, and it is possible that other unknown effects could have accounted for some of the differences observed. The aim of the present study was to document the consequences of choosing a commercially available, HCLP diet over a LCHP diet. Although premium feline dry diets contain lower amounts of carbohydrate, the HCLP diet used in the present study is typical of the low-priced dry cat foods available in supermarkets in Australia. The LCHP diet is lower in carbohydrate than typical premium maintenance feline diets, but is at the high end of prescription LCHP diets recommended for diabetic cats. To further compare lowand high-carbohydrate diets, studies of diets identical except for macronutrient amount should be compared. In addition, diets with lesser amounts of carbohydrate (e.g. 40\% ME) need to be investigated to determine whether differences in energetic efficiency are also evident when more moderate levels of carbohydrate are fed ad libitum to promote weight gain. Although ad libitum feeding is the most common feeding method employed by owners of cats, it clearly promotes weight gain, which is a risk factor for a number of feline diseases including diabetes mellitus and reduces life span, and therefore is not recommended ${ }^{(12,49)}$.

\section{Conclusions}

In cats fed to maintain ideal body weight, HCLP diets result in higher postprandial glucose and insulin concentrations compared with LCHP diets. The effects on postprandial plasma glucose and insulin concentrations in lean cats fed the HCLP diet are similar to the effects on glucose and insulin concentrations associated with the levels of weight gain observed in the present study. In cats fed ad libitum, the LCHP diet promotes greater weight gain than the HCLP diet, but when fed at maintenance energy requirements, this diet may reduce the demand on $\beta$-cells to secrete insulin. When consumed ad libitum at amounts that result in weight gain, the HCLP diet results in diarrhoea in a majority of cats, and is associated with reduced energetic efficiency for weight gain.

\section{Acknowledgements}

The authors would like to thank the WALTHAM Centre for Pet Nutrition for the financial support, and David Alexander, Lyn Knott, Maree Maher, Philippa Williams, Helen Kwan, Rebekah Scotney, Melita Watkins and Karen Tuck for their valuable assistance. This study was supported by an Australian Research Council Linkage Grant and the WALTHAM Centre for Pet Nutrition (Masterfoods Australia and New Zealand). M. C. conducted the study as part of her PhD thesis, being involved in the design of the study, data collection, analyses of the results, interpretation of the data and writing of the manuscript; J. S. R. was involved in the study design, analyses of the results, interpretation of the data and writing of the manuscript; J. M. M. was involved in the statistical analyses of the results, interpretation of the data and writing of the manuscript; J. M. R. from the Waltham Centre for Pet Nutrition was involved in assisting with the study design, interpretation of the data, writing of the manuscript, and the decision to submit it for publication. M. C., J. S. R. and J. M. M. report no real or perceived vested interests that relate to this manuscript (including relationships with the granting body or other entities whose products or services are related to topics covered in this manuscript) that could be construed as a conflict of interest. J. M. R. declares that, as an employee of Mars Incorporated, he has potential conflict of interest, since all diets used in the study were Mars products.

\section{References}

1. Kienzle E (1993) Carbohydrate metabolism of the cat. 3. Digestion of sugars. J Anim Physiol Anim Nutr 69, 203-210.

2. Kienzle E (1993) Carbohydrate metabolism of the cat. 1. Activity of amylase in the gastrointestinal tract of the cat. J Anim Physiol Anim Nutr 69, 92-101.

3. Kienzle E (1993) Carbohydrate metabolism of the cat. 2. Digestion of starch. J Anim Physiol Anim Nutr 69, 102-114.

4. Kienzle E (1993) Carbohydrate metabolism of the cat. 4. Activity of maltase, isomaltase, sucrase and lactase in the gastrointestinal tract in relation to age and diet. J Anim Physiol Anim Nutr 70, 89-96.

5. Kienzle E (1994) Effect of carbohydrates on digestion in the cat. J Nutr 124, 2568S-2571S.

6. Eisert R (2011) Hypercarnivory and the brain: protein requirements of cats reconsidered. J Comp Physiol B 181, 1-17.

7. Hewson-Hughes AK, Gilham MS, Upton S, et al. (2011) The effect of dietary starch level on postprandial glucose and insulin concentrations in cats and dogs. BrJ Nutr 106, S105-S109.

8. Bennett N, Greco DS, Peterson ME, et al. (2006) Comparison of a low carbohydrate-low fiber diet and a moderate carbohydrate-high fibre diet in the management of feline diabetes mellitus. J Feline Med Surg 8, 73-84.

9. Rand J (1999) Current understanding of feline diabetes: part 1, pathogenesis. J Feline Med Surg 1, 143-153.

10. Stumvoll M, Goldstein BJ \& Van Haeften TW (2005) Type 2 diabetes: principles of pathogenesis and therapy. Lancet 365, 1333-1346.

11. Rand JS, Fleeman LM, Farrow HA, et al. (2004) Canine and feline diabetes mellitus: nature or nurture? J Nutr 134, 2072S-2080S.

12. Scarlett JM \& Donoghue S (1998) Associations between body condition and disease in cats. J Am Vet Med Assoc 212, 1725-1731.

13. Appleton DJ, Rand JS \& Sunvold GD (2001) Insulin sensitivity decreases with obesity, and lean cats with low insulin sensitivity are at greatest risk of glucose intolerance with weight gain. J Feline Med Surg 3, 211-228.

14. Backus RC, Cave NJ \& Keisler DH (2007) Gonadectomy and high dietary fat but not high dietary carbohydrate induce gains in body weight and fat of domestic cats. Br J Nutr 98, 641-650.

15. Porte D Jr (1991) Beta cells in type II diabetes mellitus. Diabetes 40, 166-180.

16. Laflamme D (1997) Development and validation of a body condition score system for cats: a clinical tool. Feline Pract 25, 13-17.

17. Appleton DJ, Rand JS \& Sunvold GD (2005) Basal plasma insulin and homeostasis model assessment (HOMA) are 
indicators of insulin sensitivity in cats. J Feline Med Surg 7, 183-193.

18. Welch S, Gebhart SSP, Bergman RN, et al. (1990) Minimal model analysis of intravenous glucose tolerance test-derived insulin sensitivity in diabetic subjects. J Clin Endocrinol Metab 71, 1508-1518.

19. Boston RC, Stefanovski D, Moate PJ, et al. (2003) MINMOD millennium: a computer program to calculate glucose effectiveness and insulin sensitivity from the frequently sampled intravenous glucose tolerance test. Diabetes Technol Ther 5, 1003-1015.

20. Appleton DJ, Rand JS, Priest J, et al. (2001) Determination of reference values for glucose tolerance, insulin tolerance and insulin sensitivity tests in clinically normal cats. Am J Vet Res 62, 630-636.

21. Marshall RD, Rand JS \& Morton JM (2008) Glargine and protamine zinc insulin have a longer duration of action and result in lower mean daily glucose concentrations than lente insulin in healthy cats. J Vet Pharmacol Ther 31, 205-212.

22. Rowland M \& Tozer TN (1989) Assessment of area. In Clinical Pharmacokinetics: Concepts and Applications, pp. 459-471. Philadelphia, PA: Lea and Febiger.

23. Earle KE \& Smith PM (1991) Digestible energy requirements of adult cats at maintenance. J Nutr 121, S45-S46.

24. Kienzle E, Edtstadtler-Pietsch G \& Rudnick R (2006) Restrospective study on the energy requirements of adult colony cats. J Nutr 136, 1973S-1975S.

25. Hosmer DW, Lemeshow S \& May S (2008) Applied Survival Analysis. Hoboken, NJ: John Wiley and Sons.

26. Hewson-Hughes AK, Hewson-Hughes VL, Miller AT, et al. (2011) Geometric analysis of macronutrient selection in the adult domestic cat, Felis catus. J Exp Biol 214, 1039-1051.

27. Wylie-Rosett J \& Davis NJ (2009) Low-carbohydrate diets: an update on current research. Curr Diab Rep 9, 396-404.

28. Kienzle E (1994) Blood sugar levels and renal sugar excretion after the intake of high carbohydrate diets in cats. J Nutr 124, 2563S-2567S.

29. Meyer H \& Kienzle E (1991) Dietary protein and carbohydrates: relationship to clinical disease. In Proceedings of the Purina International Nutrition Symposium, Orlando, pp. $13-26$.

30. National Research Council (2006) Nutrient requirements of dogs and cats. In Carbohydrates and fiber, pp. 49-80. Washington, DC: National Academies Press.

31. Herdt $T$ (2002) Gastrointestinal physiology and metabolism. In Textbook of Veterinary Physiology, pp. 222-372 [JG Cunningham, editor]. Philadelphia, PA: WB Saunders.

32. Case LP, Carey DP, Hirakawa DA, et al. (2000) Basics of nutrition. In Canine and Feline Nutrition, pp. 1-70. St Louis, MO: Mosby.

33. Nguyen PG, Dumon HJ, Siliart BS, et al. (2004) Effects of dietary fat and energy on body weight and composition after gonadectomy in cats. Am J Vet Res 65, 1708-1713.

34. Forbes GB (2003) Some adventures in body composition, with special reference to nutrition. Acta Diabetol $\mathbf{4 0}$, S238-S241.
35. Newman AB, Lee JS, Visser M, et al. (2005) Weight change and the conservation of lean mass in old age: the Health, Aging and Body Composition Study. Am J Clin Nutr 82, 872-878.

36. Floyd JC, Fajans SS, Conn JW, et al. (1966) Stimulation of insulin secretion by amino acids. J Clin Invest $\mathbf{4 5}$ 1487-1502.

37. Daniel PM, Pratt OE \& Spargo E (1977) The metabolic homoeostatic role of muscle and its function as a store of protein. Lancet 310, 446-448.

38. Nguyen P, Dumon H, Buttin P, et al. (1994) Composition of meal influences changes in postprandial incremental glucose and insulin in healthy dogs. $J$ Nutr 124, 2707S-2711S.

39. Wolever TMS \& Bolognesi C (1996) Prediction of glucose and insulin responses of normal subjects after consuming mixed meals varying in energy, protein, fat, carbohydrate and glycemic index. J Nutr 126, 2807-2812.

40. Appleton DJ, Rand JS, Priest J, et al. (2004) Dietary carbohydrate source affects glucose concentrations, insulin secretion, and food intake in overweight cats. Nutr Res $\mathbf{2 4}$, $447-467$.

41. de-Oliveira LD, Carciofi AC, Oliveira MCC, et al. (2008) Effects of six carbohydrate sources on diet digestibility and postprandial glucose and insulin responses in cats. J Anim Sci 86, 2237-2246.

42. Ceriello A \& Colagiuri S (2008) International Diabetes Federation guideline for management of postmeal glucose: a review of recommendations. Diabet Med 25, 1151-1156.

43. McCann TM, Simpson KE, Shaw DJ, et al. (2007) Feline diabetes mellitus in the UK: the prevalence within an insured cat population and a questionnaire-based putative risk factor analysis. J Feline Med Surg 9, 289-299.

44. Lindmark S, Lönn L, Wiklund U, et al. (2005) Dysregulation of the autonomic nervous system can be a link between visceral adiposity and insulin resistance. Obes Res 13, 717-728.

45. Pietiläinen KH, Rissanen A, Kaprio J, et al. (2005) Obesity is associated with increased liver fat, intra-abdominal fat, and insulin resistance in young adult monozygotic twins. Am J Physiol Endocrinol Metab 288, E768-E774.

46. Finegood DT, Hramiak IM \& Dupre J (1990) A modified protocol for estimation of insulin sensitivity with the minimal model of glucose kinetics in patients with insulin-dependent diabetes. J Clin Endocrinol Metab 70, 1538-1549.

47. Best JD, Kahn SE, Ader M, et al. (1996) Role of glucose effectiveness in the determination of glucose tolerance. Diabetes Care 19, 1018-1030.

48. Roden M, Perseghin G, Petersen KF, et al. (1996) The roles of insulin and glucagon in the regulation of hepatic glycogen synthesis and turnover in humans. J Clin Invest 97, 642-648.

49. Lund EM, Armstrong PJ, Kirk CA, et al. (2005) Prevalence and risk factors for obesity in adult cats from private US veterinary practices. Intern J Appl Res Vet Med 3, 88-96.

50. National Research Council (2006) Energy. In Nutrient Requirements of Dogs and Cats, pp. 28-48. Washington, DC: National Academy Press.

51. National Research Council (1985) Nutrient requirements and signs of deficiency. In Nutrient Requirements of Dogs, pp. 2-38. Washington, DC: National Academy Press. 